\begin{tabular}{|c|c|}
\hline Title & $\begin{array}{l}\text { Efficient chemoselective hy drogenation of organic azides catalyzed by palladium nanoparticles with al ky ne derived } \\
\text { homogeneous supports }\end{array}$ \\
\hline Author(s) & A rai, Noriyoshi; Onodera, Nozomi; Ohkuma, Takeshi \\
\hline Citation & $\begin{array}{l}\text { Tetrahedron Letters, } 57(37), 4183-4186 \\
\text { https://doi.org/10.1016/.tetlet.2016.08.002 }\end{array}$ \\
\hline Issue Date & 2016-09-14 \\
\hline Doc URL & http:/hdl.handle.net/2115//1461 \\
\hline Rights & $\begin{array}{l}\text { (9 2016. This manuscript version is made available under the CC-BY-NC-ND } 4.0 \text { license } \\
\text { http://reativecommons.org/icenses/by-nc-nd/4.0/ }\end{array}$ \\
\hline Rights(URL) & http://creativecommons.org/icenses/by-nc-nd/4.0/ \\
\hline Type & article (author version) \\
\hline File Information & OhkumaTL57(37).pdf \\
\hline
\end{tabular}

Instructions for use 


\section{Graphical Abstract}

To create your abstract, type over the instructions in the template box below.

Fonts or abstract dimensions should not be changed or altered.

\section{Efficient chemoselective hydrogenation of organic azides catalyzed by palladium nanoparticles with alkyne-derived homogeneous supports}

Noriyoshi Arai, Nozomi Onodera, and Takeshi Ohkuma*

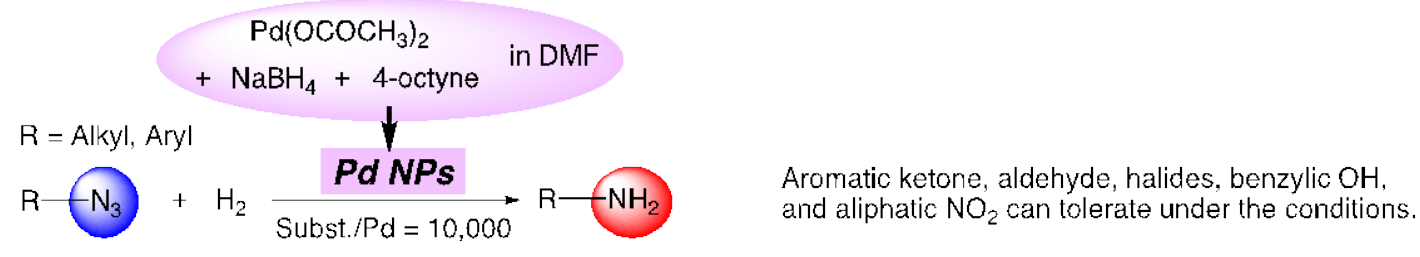




\title{
Efficient chemoselective hydrogenation of organic azides catalyzed by palladium nanoparticles with alkyne-derived homogeneous supports
}

\author{
Noriyoshi Arai ${ }^{\mathrm{a}}$, Nozomi Onodera ${ }^{\mathrm{a}}$, and Takeshi Ohkuma ${ }^{\mathrm{a}}$ * \\ ${ }^{a}$ Division of Applied Chemistry and Frontier Chemistry Center, Faculty of Engineering, Hokkaido University, Sapporo, Hokkaido 060-8628, Japan
}

\section{ARTICLE INFO}

\section{ABSTRACT}

\section{Article history:}

Received

Received in revised form

Accepted

Available online

\section{Keywords:}

Palladium

Nanoparticles

Hydrogenation

Organic azide

Chemoselective

\begin{abstract}
Catalytic chemoselective hydrogenation of organic azides using palladium nanoparticles stabilized by alkyne derivatives was studied. A broad range of aromatic and aliphatic azides were smoothly reduced to the corresponding amines in excellent yields with a quite small amount of the catalyst. Hydrogenation of 3-phenylpropylazide gave 3-phenylpropylamine almost quantitatively with a substrate-to-palladium molar ratio (S/Pd) of 12,900 under 8 atm of $\mathrm{H}_{2}$. The reaction under $1 \mathrm{~atm}$ of $\mathrm{H}_{2}$ also proceeded smoothly with an S/Pd of 1,000. Several reduction-sensitive functional groups, such as carbonyl, halide, benzylic $\mathrm{OH}$, and aliphatic nitro were well tolerated under the reaction conditions.
\end{abstract}

2009 Elsevier Ltd. All rights reserved.
Amines are quite important compounds in various research fields, including pharmaceuticals, dyes, agrochemicals, and so on. ${ }^{1}$ Reduction of azides is one of the simplest and most reliable methods for the preparation of amines. ${ }^{2}$ Although a number of reactions have been reported for this important transformation, ${ }^{3-5}$ catalytic hydrogenation is superior to the others both from an economical and ecological point of view, especially in a large scale preparation. ${ }^{6}$ Palladium(0) supported on charcoal is widely used as a catalyst in this reaction. ${ }^{7}$ However, problems in chemoselectivity are occasionally encountered when the substrate contains functional groups sensitive under the reaction conditions of hydrogenation. ${ }^{8,9}$ To address this issue, deliberately designed catalysts have been developed for the chemoselective hydrogenation. ${ }^{10,11}$

We recently reported novel palladium nanoparticles (Pd NPs 1) prepared from $\mathrm{Pd}\left(\mathrm{OCOCH}_{3}\right)_{2}$ and 2 equiv of $t-\mathrm{C}_{4} \mathrm{H}_{9} \mathrm{OK}(\mathbf{1 a})$ or $\mathrm{NaBH}_{4}$ (1b) with 10 equiv of 4-octyne in DMF at ambient temperature for $12 \mathrm{~h}$ (Scheme 1). ${ }^{12}$ Pd NPs 1 in DMF (10 mM) are homogeneously dispersed and have a shelf-life of more than a year at ambient temperature without aggregation. These Pd NPs exhibited excellent catalytic activity in selective partial hydrogenation of alkynes and chemoselective hydrogenation of nitroarenes. ${ }^{12,13}$ In the course of our study, we found that the Pd NPs $\mathbf{1 b}$ efficiently catalyze chemoselective hydrogenation of aryl and alkyl azides. Here, we would like to describe the features of the convenient functional group transformation.

$\mathrm{Pd}\left(\mathrm{OCOCH}_{3}\right)_{2} \quad \begin{gathered}\text { reagent } \\ \text { 4-octyne }\end{gathered} \stackrel{\text { DMF, rt, 12 h }}{\text { Pd NPs } 1}$

Scheme 1. Preparation of Pd NPs 1.

1a: reagent $=t$-BuOK

1b: reagent $=\mathrm{NaBH}_{4}$

We chose 3-phenylpropylazide (3a) as a standard substrate to optimize the reaction conditions (Table 1). When the azide 3a was hydrogenated in THF at $50{ }^{\circ} \mathrm{C}$ under 8 atm of hydrogen in the presence of a catalytic amount of Pd NPs $\mathbf{1 b}$ (substrate-topalladium molar ratio $(\mathrm{S} / \mathrm{Pd})=1.3 \times 10^{4}$, loaded as a $5.0 \mathrm{mM}$ DMF solution), the reaction was completed within $16 \mathrm{~h}$ to give 3phenylpropylamine (4a) in nearly quantitative yield (Table 1 , Entry 1). The S/Pd per time-to-full conversion $\left(\mathrm{TOF}_{\mathrm{av}}\right)$ was $7.9 \times 10^{2} \mathrm{~h}^{-1}$. The reaction also proceeded under atmospheric pressure of hydrogen (Entry 2). The starting material 3a was completely consumed, but the yield of 4a was $79 \%$. ${ }^{1} \mathrm{H}$ NMR analysis of the crude reaction mixture showed that remaining $\mathbf{3 a}$ was converted to dimeric imine, though the reaction pathway was not clear. THF was a solvent of choice, but methanol, ether, and hexane were also useful solvents (Entries 3-5). On the other hand, the reactions in toluene, dichloromethane, and ethyl acetate were much slower than those in the solvents described above, resulting in unsatisfactory product yields (Entries 6-8). 
Table 1. Hydrogenation of Azide 3a Catalyzed by Pd NPs 1b

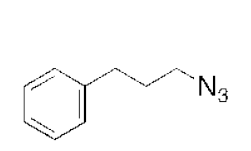

$3 a$

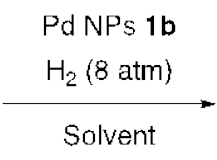

$50^{\circ} \mathrm{C}, 16 \mathrm{~h}$

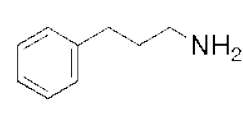

$4 a$
Table 2. Substrate Scope in the Hydrogenation of Azides 3 with Pd NPs 1b

$$
\begin{array}{ccc} 
& \multicolumn{2}{c}{\text { Pd NPs 1b }} \\
\mathrm{R}-\mathrm{N}_{3} & \mathrm{H}_{2}(8 \mathrm{~atm}) \\
\cline { 2 - 2 } & \begin{array}{c}
\text { Solvent, } 50^{\circ} \mathrm{C} \\
8-46 \mathrm{~h}
\end{array} & \mathrm{R}-\mathrm{NH}_{2} \\
3 & & 4
\end{array}
$$<smiles>NCCCc1ccccc1</smiles><smiles>CC(=O)c1ccc(N)cc1</smiles>

4b

4d<smiles>NCc1ccc(Br)cc1</smiles><smiles>NCc1ccc(Cl)cc1</smiles><smiles>NCC(O)c1ccccc1</smiles><smiles>NCc1cccs1</smiles><smiles>O=Cc1ccc(CNC(=O)OCc2ccccc2)cc1</smiles>

4] transformation. Hydrogenation of a range of aromatic and aliphatic azides was carried out, and the results are summarized in Table 2. Hydrogenation of azide 3a proceeded smoothly to give the corresponding amine $\mathbf{4 a}$, which was isolated as Boc carbamate with a slight loss of the product (Entry 1). Benzyl, phenyl, and cyclohexyl azides (3b-d) were also successfully converted to the amines in high yields (Entries 2-5). Methanol could be employed as well as THF in some cases. In the hydrogenation of 4'-azidoacetophenone (3e), the azide moiety was selectively reduced to amine without loss of the carbonyl group to afford 4'-aminoacetophenone (4e) in excellent yield (Entry 6). ${ }^{14}$ We generally performed the reactions under gentle warming in a water bath in order to secure the catalyst activity and to keep the temperature constant throughout the reaction; however, the reaction could also be carried out at ambient temperature (Entry 7). It should be noted that the hydrogenation of 4-halobenzyl azides (3f and $\mathbf{3 g}$ ) gave the amines $\mathbf{4 f}$ and $\mathbf{4 g}$ without hydrogenolysis of the halide moieties (Entry 8 and 9). ${ }^{15}$ The hydroxy group at the benzylic position remained intact throughout the hydrogenation of $\mathbf{3 h}$ to give the amine $\mathbf{4 h}$ in nearly quantitative yield (Entry 10). ${ }^{16}$ Unfortunately, the hydrogenation of thienyl azide $3 \mathbf{i}$ hardly proceeded, even with a relatively large amount of the catalyst, probably due to poisoning by sulfur (Entry 11). In the hydrogenation of 4-formylbenzyl azide, azide group was hydrogenated faster than formyl group. The reaction must be carried out in the presence of $\mathrm{Boc}_{2} \mathrm{O}$ to avoid self-condensation, although the addition of $\mathrm{Boc}_{2} \mathrm{O}$ caused retardation of the reaction. The starting material $\mathbf{3 j}$ was consumed in $46 \mathrm{~h}$ to give $\mathbf{4 i}$ in $53 \%$ yield, accompanied by the formation of $p$-phthaldehyde, 4-cyanobenzaldehyde (apprx. 5\% each), and a mixture of unidentified compounds (Entry 12). Selective hydrogenation in the presence of alkene moiety turned out to be difficult.

Chemoselective hydrogenation of azides catalyzed by palladium on boron nitride was reported. ${ }^{11 a}$ The amine products were obtained with keeping functionalities, such as ketone, nitro, alkene, and benzylic ester intact. The catalyst turnover number reached to 990. Though our catalytic system has room for improvement in the chemoselectivty, it has an advantage over the preceding method from a standpoint of catalyst turnover.

\begin{tabular}{cccccc}
\hline Entry & $\mathbf{3}$ & S/Pd & Solvent & Time $(\mathrm{h})$ & Yield of $\mathbf{4}^{\mathrm{a}}(\%)$ \\
\hline 1 & $\mathbf{3 a}$ & 12900 & $\mathrm{THF}$ & 16 & $>99(87)^{\mathrm{b}, \mathrm{c}}$ \\
2 & $\mathbf{3 b}$ & 10800 & $\mathrm{THF}$ & 21.5 & $99(88)^{\mathrm{b}, \mathrm{c}}$ \\
3 & $\mathbf{3 b}$ & 11000 & $\mathrm{CH}_{3} \mathrm{OH}$ & 24 & 83 \\
4 & $\mathbf{3 c}$ & 1100 & $\mathrm{CH}_{3} \mathrm{OH}$ & 24 & 94 \\
5 & $\mathbf{3 d}$ & 5100 & $\mathrm{THF}$ & 24 & $94(84)^{\mathrm{b}, \mathrm{d}}$ \\
6 & $\mathbf{3 e}$ & 10000 & $\mathrm{THF}$ & 18 & $99(93)^{\mathrm{b}}$ \\
$7^{\mathrm{e}}$ & $\mathbf{3 e}$ & 5000 & $\mathrm{CH}_{3} \mathrm{OH}$ & 8 & $>99(99)^{\mathrm{b}}$ \\
8 & $\mathbf{3 f}$ & 4900 & $\mathrm{THF}$ & 24 & $89(78)^{\mathrm{b}, \mathrm{c}}$ \\
9 & $\mathbf{3 g}$ & 5600 & $\mathrm{THF}$ & 22 & $86(94)^{\mathrm{b}, \mathrm{b}, \mathrm{t}}$ \\
10 & $\mathbf{3 h}$ & 9900 & $\mathrm{THF}$ & 24 & $>99(99)^{\mathrm{b}, \mathrm{c}}$ \\
11 & $\mathbf{3 i}$ & 2000 & $\mathrm{THF}$ & 24 & 53 \\
$12^{\mathrm{g}}$ & $\mathbf{3 j}$ & 5000 & THF & 46 & $52(53)^{\mathrm{b}}$ \\
\hline
\end{tabular}

${ }^{a}$ Estimated by ${ }^{1} \mathrm{H}$ NMR by using 1,3,5-trimethoxybenzene (Entries 2-4, 6-8), triphenylmethane (Entry 5, 9, and 12), or 1,1,2,2-tetrachloroethane (Entries 1, 10, and 11) as an internal standard.

${ }^{\mathrm{b}}$ The isolated yield is given in parentheses.

${ }^{\mathrm{c}}$ Isolation was carried out after Boc protection.

${ }^{\mathrm{d}}$ Isolation was carried out after benzoylation.

${ }^{\mathrm{e}}$ Carried out at ambient temperature.

${ }^{\mathrm{f}}$ Small amounts (apprx. 10\%) of homodimeric imine were detected in the crude mixture (see ref.18). The isolated yield higher than NMR yield was attributed to reproduction of amine $\mathbf{4 g}$ by the hydrolysis of the imine during Boc protection.

${ }^{\mathrm{g}}$ The hydrogenation was carried out in the presence of $\mathrm{Boc}_{2} \mathrm{O}$ in order to avoid self-condensation.

To demonstrate the chemoselective feature of this catalyst, we compared the hydrogenation of $\mathbf{3 e}$ by using conventional hydrogenation conditions with commercially available $\mathrm{Pd} / \mathrm{C}$ (Scheme 2). ${ }^{17}$ When the azide 3e was hydrogenated at $25^{\circ} \mathrm{C}$ under $1 \mathrm{~atm}$ of hydrogen in the presence of Pd NPs $\mathbf{1 b}(3 \mathbf{e} / \mathrm{Pd}$ molar ratio was 1000), 4'-aminoacetophenone (4e) was produced quantitatively, with complete retention of the carbonyl moiety without any control of the reaction. In marked contrast, hydrogenation of $3 \mathbf{e}$ under typical reaction conditions with commercial $\mathrm{Pd} / \mathrm{C}(10 \%)$ gave about $10 \%$ of over-reduced compounds $\mathbf{5}$ and $\mathbf{6}$ as byproducts. Although, we can not rule out the possibility that $\mathbf{4 e}$ would be selectively obtained by stopping the reaction at an earlier stage, much care must be taken to avoid over reduction. 

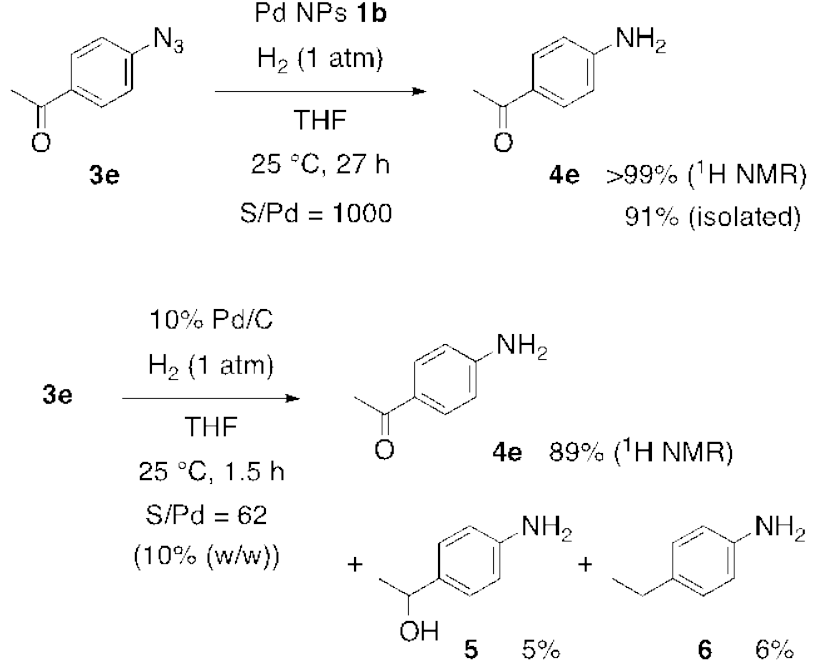

Scheme 2. Comparison with commercial Pd/C.

Since we already found that the Pd NPs 1b shows excellent catalytic activity in the hydrogenataion of aromatic nitro compounds, ${ }^{13}$ chemoselective reduction of azide over aromatic nitro group seems difficult. However, an aliphatic azide 3a was hydrogenated prior to an aliphatic nitro compound $\mathbf{7}$ as demonstrated in Scheme 3. The competitive reaction was conducted under the typical conditions. The Boc-protected amine 4a was obtained in high yield after treatment with $\mathrm{Boc}_{2} \mathrm{O}$, while nitro compound 7 was recovered quantitatively.
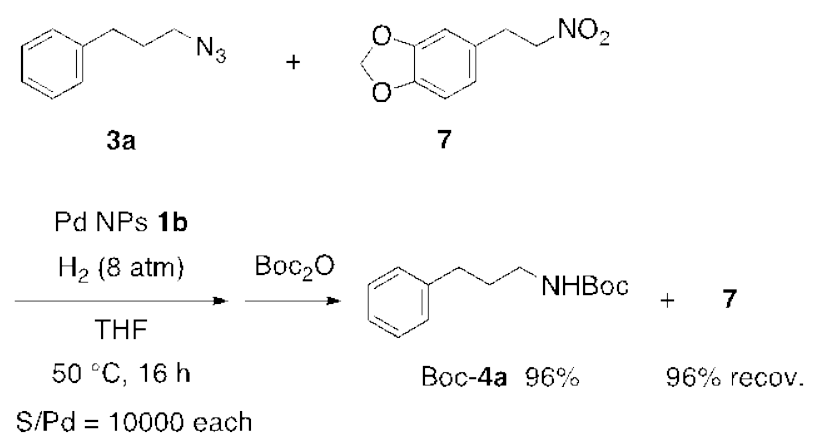

Scheme 3. Competitive reaction between azide $3 \mathbf{a}$ and nitro compound 7.

It may be worth noting that the Pd NPs $\mathbf{1 b}$ can be handled as dilute stock solution with a shelf-life of longer than one year under the air and easily added to a reaction mixture in very small amounts, whereas the solid $\mathrm{Pd} / \mathrm{C}$ is occasionally susceptible to poisoning by impurities in its use of very small quantity.

In summary, the Pd NPs stabilized by alkyne derivatives exhibit excellent catalytic activity in hydrogenation of organic azide compounds. The substrate-to-palladium molar ratio reaches over $10^{4}$. The reaction under atmospheric pressure of hydrogen is also available. A range of aromatic and aliphatic azides that have a sensitive functional group under reductive conditions are hydrogenated to the corresponding amines in high yields, while retaining their sensitive functionality.

\section{Acknowledgments}

This work was supported by Grants-in-Aid from the Japan Society for the Promotion of Science (JSPS) (No. 15H03802) and the MEXT (Japan) program "Strategic Molecular and Materials Chemistry through Innovative Coupling Reactions" of Hokkaido University.

\section{References and notes}

1. (a) Travis, A. S. In The Chemistry of Anilines, Part 1; Rappoport, Z., Ed.; Wiley: Chicherster, 2007; p. 1; (b) Kahl, T.; Schröder, K.W.; Lawrence, F. R.; Marshall, W. J.; Höke, H.; Jäckh, R. Ullmann's Encyclopedia of Industrial Chemistry; Wiley-VCH: Weinheim, 2011. Aniline; (c) Franzen, F.; Eysell, K. Biologically Active Amines Found in Man: Their Biochemistry, Pharmacology, and Pathophysiological Importance; Pergamon Press: Oxford, New York, 1969.

2. (a) Haase, J. In Organic Azides: Synthesis and Applications; Bräse, S.; Banert, K., Eds.; Wiley: Chicherster, 2009; p. 29; (b) Scriven, E. F. V.; Turnbull, K. Chem. Rev. 1988, 88, 297.

3. Reduction by metal hydride reagents: (a) Maddani, M. R.; Moorthy, S. K.; Prabhu, K. R. Tetrahedron 2010, 66, 329; (b) Fringuelli, F.; Pizzo, F.; Vaccaro, L. Synthesis 2000, 646; (c) Hays, D. S.; Fu, G. C. J. Org. Chem. 1998, 63, 2796; (d) Raja Ram, S.; Charly, K.P.; Iyengar, D. S. Synth. Commun. 2000, 30, 4495; (e) Sun, J.-H.; Teleha, C. A.; Yan, J.-S.; Rodgers, J. D.; Nugiel, D. A J. Org. Chem. 1997, 62, 5627; (f) Salunkhel, A. M.; Brown, H. C. Tetrahedron Lett. 1995, 36, 7987; (g) Ranu, B. C.; Sarkar, A.; Chakraborty, R. J. Org. Chem. 1994, 59, 4114; (h) Rao, H. S. P.; Siva, P. Synth. Commun. 1994, 24, 549; (i) Yoon, N. M.; Choi, J.; Young, S. Synth. Commun. 1993, 23, 3047; (j) Soai, K.; Yokoyama, S.; Ookawa, A. Synthesis 1987, 48; (k) Rolla, F. J. Org. Chem. 1982, 47, 4327.

4. Reduction by low valent metal reagents: (a) Reddy, G. V.; Rao, G. V.; Iyengar, D. S. Tetrahedron Lett. 1999, 40, 3937; (b) Huang, Y.; Zhang, Y.; Wang, Y. Tetrahedron Lett. 1997, 38, 1065; (c) Goulaouic-Dubois, C.; Hesse, M. Tetrahedron Lett. 1995, 36, 7427; (d) Fitz, W.; Schwark, J.-R.; Wong, C.-H. J. Org. Chem. 1995, 60, 3663; (e) Mati, S. N.; Spevak, P.; Reddy, A. V. N. Synth. Commun. 1988, 18, 1201.

5. Reduction by phosphines, sulfides, and other reagents: (a) Cantillo, D.; Moghaddam, M. M.; Kappe, C. O. J. Org. Chem. 2013, 78, 4530; (b) Kamal, A.; Shankaraiah, N.; Reddy, K. L.; Devaiah, V. Tetrahedron Lett. 2006, 47, 4253; (c) Kamal, A.; Ramana, K. V.; Ankati, H. B.; Ramana, A. V. Tetrahedron Lett. 2002, 43, 6861; (d) Kamal, A.; Rao, N. V.; Laxman, E. Tetrahedron Lett. 1997, 38, 6945; (e) Suzuki, H.; Takaoka, K. Chem. Lett. 1984, 1733; (f) Vaultier, M.; Knouzi, N.; Carrié, R. Tetrahedron Lett. 1983, 24, 763; (g) Bayley, H.; Standring, D. N.; Knowles, J. R. Tetrahedron Lett. 1978, 3633

6. (a) Brown, M. F.; Mitton-Fry, M. J.; Arcari, J. T.; Barham, R.; Casavant, J.; Gerstenberger, B. S.; Han, S.; Hardink, J. R.; Harris, T. M.; Hoang, T.; Huband, M. D.; Lall, M. S.; Lemmon, M. M.; Li, C.; Lin, J.; McCurdy, S. P.; McElroy, E.; McPherson, C.; Marr, E. S.; Mueller, J. P.; Mullins, L.; Nikitenko, A. A.; Noe, M. C.; Penzien, J.; Plummer, M. S.; Schuff, B. P.; Shanmugasundaram, V.; Starr, J. T.; Sun, J.; Tomaras, A.; Young, J. A.; Zaniewski, R. P. J. Med. Chem. 2013, 56, 5541; (b) Welschoff, N.; Waldvogel, S. R. Synthesis 2010, 3596; (c) Breitenlechner, C. B.; Wegge, T.; Berillon, L.; Graul, K.; Marzenell, K.; Friebe, W.-G.; Thomas, U.; Schumacher, R.; Huber, R.; Engh, R. A.; Masjost, B. J. Med. Chem. 2004, 47, 1375.

7. (a) Levy, J.-N.; Latham, C. M.; Roisin, L.; Kandziora, N.; Di Fruscia, P.; White, A. J. P.; Woodward, S.; Fuchter, M. J. Org. Biomol. Chem. 2012, 10, 512; (b) Saravanan, P.; Corey, E. J. J. Org. Chem. 2003, 68, 2760; (c) Carboni, B.; Benalil, A.; Vaultier, M. J. Org. Chem. 1993, 58, 3736; (d) Moore, A. T.; Rydon, H. N. Org. Synth., Coll. Vol. 5 1973, 586.

8. (a) Soliman, S. E.; Kováč, P. J. Org. Chem. 2015, 80, 4851. (b) Jean-Gérard, L.; Macé, F.; Ngo, A. N.; Pauvert, M.; Dentel, H.; Evain, M.; Collet, S.; Guingant, A. Eur. J. Org. Chem. 2012, 4240. (c) Lamb, P. B.; McElhinny, C. J.; Sninski, T.; Purdom, H.; Carroll, F. I.; Lewin, A. H. J. Labelled Compd. Radiopharm. 2009, 52, 457. (d) Banwell, M. G.; Haddad, N.; Hudlicky, T.; Nugent, T. C.; Mackay, M. F.; Richards, S. L. J. Chem. Soc., Perkin 1 1997, 1779. (e) Plé, N.; Turck, A.; Couture, K.; Quéguiner, G. Synthesis 1996, 838. 


\section{Tetrahedron}

9. (a) Sweis, R. F.; Wang, Z.; Algire, M.; Arrowsmith, C. H.; Brown, P. J.; Chiang G. G.; Guo, J.; Jakob, C. G.; Kennedy, S.; Li, F.; Maag, D.; Shaw, B.; Soni, N. B.; Vedadi, M.; Pappano, W. N. ACS Med. Chem. Lett. 2015, 6, 695. (b) Schrittwieser, J. H.; Coccia, F.; Kara,S.; Grischek, B.; Kroutil, W.; d'Alessandrod, N.; Hollmann, F. Green Chem. 2013, 15, 3318. (c) Bughin, C.; Masson, G.; Zhu, J. J. Org. Chem. 2007, 72, 1826. (d) Boruwa, J.; Borah, J. C.; Gogoi, S.; Barua, N. C. Tetrahedron Lett. 2005, 46, 1743.

10. (a) Ahammed, S.; Saha, A.; Ranu, B. C. J. Org. Chem. 2011, 76, 7235; (b) Hemantha, H. P.; Sureshbabu, V. V. Org. Biomol. Chem. 2011, 9, 2597; (c) Cho, B. T.; Kang, S. K.; Shin, S. H. Tetrahedron: Asymmetry 2002, 13, 1209: (d) Kantam, M. L.; Chowdari, N. S.; Rahman, A.; Choudary, B. M. Synlett 1999 , 1413; (e) Corey, E. J.; Nicolaou, K. C.; Balanson, R. D.; Machida, Y. Synthesis 1975, 590.

11. (a) Yabe, Y.; Sawama, Y.; Yamada, T.; Nagata, S.; Monguchi, Y.; Sajiki, H. ChemCatChem 2013, 5, 2360; (b) Esaki, H.; Hattori, T.; Tsubone, A.; Mibayashi, S.; Sakata, T.; Sawama, Y.; Monguchi, Y.; Yasuda, H.; Nosaka, K.; Sajiki, H. ChemCatChem 2013, 5, 3629; (c) Takahashi, T.; Yoshimura, M.; Suzuka, H.; Maegawa, T.; Sawama, Y.; Monguchi, Y.; Sajiki, H. Tetrahedron 2012, 68, 8293; (d) Maegawa, T.; Takahashi, T.; Yoshimura, M.; Suzuka, H.; Monguchi, Y.; Hironao Sajiki, H. Adv. Synth. Catal. 2009, 351 2091; (c) Mori, A.; Mizusaki, T.; Kawase, M.; Maegawa, T.; Monguchi, Y.; Takao, S.; Takagi, Y.; Sajiki, H. Adv. Synth. Catal. 2008, 350, 406; (f) Ikawa, T.; Sajiki, H.; Hirota, K. Tetrahedron 2005, 61, 2217; (g) Hattori, K.; Sajiki, H.; Hirota, K. Tetrahedron 2000, 56, 8433.

12. Hori, J.; Murata, K.; Sugai, T.; Shinohara, H.; Noyori, R.; Arai, N.; Kurono, N.; Ohkuma, T. Adv. Synth. Catal. 2009, 351, 3143.

13. Arai, N.; Onodera, N.; Dekita, A.; Hori, J.; Ohkuma, T. Tetrahedron Lett. 2015, 56, 3913.
14. Aromatic ketones are easily reduced to the corresponding alcohols under hydrogenation conditions with Pd/C. See: Deodhar, M.; StC Black,D.; Kumar, N. Tetrahedron 2007, 63, 5227.

15. $\mathrm{Pd} / \mathrm{C}$ is an efficient catalyst for the hydrogenolysis of arylhalides; see: Baltzly, R.; Phillips, A. P. J. Am. Chem. Soc. 1946, 68, 261. See also ref. 8.

16. Benzylic hydroxy groups are replaced with hydrogen under hydrogenation conditions with Pd/C. See: (a) Rob, T.; Ogi, T.; Maarisit, W.; Taira, J.; Ueda, K. Molecules 2011, 16, 9972. (b) Geng, H.; Zhang, W.; Chen, J.; Hou, G.; Zhou, L.; Zou, Y.; Wu, W.; Zhang. X. Angew. Chem. Int. Ed. 2009, 48, 6052.

17. Takahashi, K.; Yamagishi, G.; Hiramatsu, T.; Hosoya, A.; Onoe, K.; Doi, H.; Nagata, H.; Wada, Y.; Onoe, H.; Watanabe, Y.; Hosoya, T. Bioorg. Med. Chem. 2011, 19, 1464.

18. Formation of homodimeric imines from benzylic azides catalyzed by Pd catalyst. See: Martínez-Sarti, L.; Díez-González, S. ChemCatChem 2013, 5, 1722.

\section{Supplementary Material}

Supplementary data (preparative method of Pd NPs $\mathbf{1 b}$ and NMR spectra of compounds $\mathbf{4 a - j}$ ) associated with this article can be found, in the online version, at http://dx.doi.org/10.1016/j.tetlet.\#\#\#.

\section{Click here to remove in struction text...}

